\title{
POST NATAL MANAGEMENT OF ANTENATALLY DETECTED HYDRONEPHROSIS
}

\author{
Ravikumar Jadav ${ }^{1}$, Manjuprasad G. B2
}

${ }_{1}^{1}$ Associate Professor, Department of Urology, KIMS, Hubli, Karnataka, India.

${ }^{2}$ Associate Professor, Department of Urology, KIMS, Hubli, Karnataka, India.

\section{BACKGROUND}

ABSTRACT

Ultrasound screening during pregnancy has resulted in increasing recognition of foetal hydronephrosis. Depending on diagnostic criteria and gestation, the prevalence of antenatally detected hydronephrosis (ANH) ranges from 0.6 to $5.4 \%$. The investigations that predict the progression of hydronephrosis and progressive loss of renal functions are limited. Pressure flow studies and diuretic renography have been developed to try to predict as to which dilated kidney will undergo progressive deterioration. However, in order to interpret the significance of neonatal hydronephrosis, and to apply the diagnostic tests accurately, it must be recognised that tests do not actually recognise obstruction; they merely identify, and monitor parameters shared by obstructed kidneys that seem to correlate empirically with the potential for progressive renal deterioration.

\section{MATERIALS AND METHODS}

All cases satisfying the criteria for ANH were followed up after delivery. Postnatal USG was performed, and severity was assessed. Society of Foetal Urology (SFU) grade I/II were followed up by USG. SFU grades III/IV were investigated for cause of obstruction by Micturating cystourethrogram (MCU) and Diuretic Renogram (DR) at 1 month. Surgery is performed if obstruction is identified. Patient is followed up post operatively with USG and DR.

\section{RESULTS}

The incidence of antenatal hydronephrosis was $0.134 \%$. Only patients with renal pelvic Antero Posterior Diameter (APD) $>7 \mathrm{~mm}$ in third trimester showed any post natal pathology. 100\% of patients with severe disease on antenatal scan showed post natal pathology compared to $33.33 \%$ on post natal evaluation $100 \%$ of patients with grade I/II disease showed resolution within $1 \mathrm{yr}$. $100 \%$ of patients with grade II/IV disease showed post natal pathology. Most common cause of hydronephrosis was transient cause (33.33\%) followed by PUJ obstruction (20\%).

\section{CONCLUSION}

Only patients with renal pelvic APD $>7 \mathrm{~mm}$ in third trimester have postnatal pathology, which should be taken as cut off. ANH is caused by transient cause, pelviureteric junction obstruction, megaureter, posterior urethral valves, VUR and cystic disease of kidney. Patients with SFU grade I/II HN will resolve and only need regular follow up with ultra sonogram. Patients with SFU grade III/IV will have a pathology that needs intervention. Pathology needs to be identified by MCU and Diuretic Renogram. Early relief of obstruction will prevent progressive renal damage.

\section{KEY WORDS}

Antenatal Hydronephrosis, PUJ Obstruction, Vesico Ureteric Reflux, Posterior Urethral Valves.

HOW TO CITE THIS ARTICLE: Jadav R, Manjuprasad GB. Post natal management of antenatally detected hydronephrosis. J. Evolution Med. Dent. Sci. 2018;7(53):5587-5590, DOI: 10.14260/jemds/2018/1236

\section{BACKGROUND}

The term hydronephrosis is generally defined as dilatation of the renal pelvis and calyces resulting from intermittent and incomplete obstruction to flow of urine. Whereas, Urinary tract obstruction is clinically defined as any restriction to urinary outflow that left untreated will cause progressive renal deterioration.

Hydronephrosis, is the most common urologic abnormality found on antenatal ultrasound evaluation. It may be due to. ${ }^{1}$ Transient hydronephrosis, pelviureteric junction obstruction, vesicoureteric reflux, megaureter, multicystic dysplastic kidneys.

'Financial or Other Competing Interest': None.

Submission 24-11-2018, Peer Review 17-12-2018,

Acceptance 24-12-2018, Published 31-12-2018.

Corresponding Author:

Dr. Manjuprasad G. $B$

Associate Professor,

Department of Urology, KIMS, Hubli,

Karnataka, India.

E-mail: drpmanju@yahoo.co.in

DOI: $10.14260 /$ jemds $/ 2018 / 1236$
Posterior urethral valves and Others: Urethral atresia, Urogenital sinus, Prune belly syndrome, tumour etc.

Hydronephrosis is not necessarily progressive. It can be caused by non-obstructive phenomena such as reflux that will improve spontaneously or it may be due to congenital dysmorphism such as prune belly syndrome which remains stable throughout life. It be may also be caused by partial obstruction which will reach a state of equilibrium. It is important to identify the subset of cases with hydronephrosis who have urinary tract obstruction and progressive loss of renal function.

Ultrasound screening during pregnancy has resulted in increasing recognition of foetal hydronephrosis. Depending on diagnostic criteria and gestation, the prevalence of antenatally detected hydronephrosis (ANH) ranges from 0.6 to $5.4 \% .^{2-5}$ The condition is bilateral in $17-54 \%$ and additional abnormalities are occasionally associated. The outcome of ANH depends on the underlying aetiology. Although ANH resolves by birth or during infancy in $41-88 \%$ patients 1 urological abnormalities requiring intervention are identified in $4.1-15.4 \% 5$ and rates of vesicoureteric reflux (VUR) and urinary tract infections (UTI) are several-fold 
higher. ${ }^{1}$ It is important to distinguish infants with significant illness that require long-term follow-up or surgery, from those with transient hydronephrosis and minimum need for invasive investigations.

\section{Objectives}

1. To determine the cause of antenatal hydronephrosis and its incidence.

2. To ascertain the outcome of antenatal hydronephrosis.

\section{MATERIALS AND METHODS}

\section{Sample Size}

The sample size for the study was taken for convenience.

This is a clinical study of 20 cases of antenatal hydronephrosis, those are diagnosed during routine antenatal ultrasonogram (Total 1770 cases) admitted/followed up to/at the department of paediatric surgery and department of paediatrics, Karnataka Institute of Medical Sciences, Hubli during the period of November 2013 to September 2015. Data is presented in percentages and proportions; hence no statistical test was adopted.

All the details of ultrasound examination were recorded. Subsequent follow up scans and post natal evaluation performed as per revised guidelines for management of antenatal hydronephrosis. Patients were subjected to detailed clinical evaluation. Mothers were counselled appropriately regarding follow up and prognosis. MCU, IVP and DTPA scan were performed if indicated.

Patients were subjected to observation, minimally invasive and operative procedures depending on the diagnosis, severity and progression of hydronephrosis. Observation included ultrasonography at 1 month, 3-6 months and at $1 \mathrm{yr}$. The patients were followed up post operatively with USG and DTPA scan as indicated.

\section{RESULTS}

The observation and results of the 20 cases of antenatal hydronephrosis are summarised in the following tables.

Total number of live births in KIMS from November 2013 to August 2015 were 14918. The incidence of antenatal hydronephrosis was $0.134 \%$. In the study the average gestational age of detection of hydronephrosis was 24 wks. 5 days.

\begin{tabular}{|c|c|c|}
\hline Gestational age in Wks. & No. of Cases & Percentage \\
\hline$<16$ & 0 & 0 \\
\hline $16-20$ & 2 & $10 \%$ \\
\hline $20-24$ & 10 & $50 \%$ \\
\hline $24-28$ & 2 & $10 \%$ \\
\hline $28-32$ & 2 & $10 \%$ \\
\hline $32-36$ & 4 & $20 \%$ \\
\hline$>36$ & 0 & 0 \\
\hline \multicolumn{2}{|c|}{ Table 1. Gestational Age at Diagnosis } \\
\hline
\end{tabular}

In the study, 17 patients with hydronephrosis were male $(85 \%)$ and 2 were female (10\%). Sex of one foetus couldn't be identified as foetus was aborted at 18 wks. Male: female ratio is 8.5:1. Both female patients had cystic disease of the kidney. $35 \%$ of the cases had bilateral disease. Left side ( 7 cases, $35 \%$ ) is more common than the right (6 cases, $30 \%$ ). The severity of antenatal hydronephrosis is mild in 7 cases (35\%), moderate in 6 cases (30\%) and severe in 7 cases (35\%).

On correlation of severity of ANH with Post- natal pathology only $33.33 \%$ of patients with mild ANH had postnatal pathology. Whereas $83.33 \%$ (5/6 cases) with moderate ANH and $100 \%$ (3/3 cases) patients with severe ANH had post natal pathology.

\begin{tabular}{|c|c|c|c|}
\hline $\begin{array}{c}\text { APD of Renal } \\
\text { Pelvis in 3 }\end{array}$ & $\begin{array}{c}\text { No. of } \\
\text { Cases }\end{array}$ & $\begin{array}{c}\text { Post Natal } \\
\text { Pathology }\end{array}$ & Percentage \\
\hline $7-9 \mathrm{~mm}$ & $6^{* *}$ & 2 & $33.33 \%$ \\
\hline $10-15 \mathrm{~mm}$ & 6 & 5 & $83.33 \%$ \\
\hline$>15 \mathrm{~mm}$ & $3^{*}$ & 3 & $100 \%$ \\
\hline Table 2. Correlation of Severity of ANH with Post-Natal \\
Pathology \\
\hline * only 3 patients completely evaluated ** One baby was \\
aborted.
\end{tabular}

Among 20 cases of hydronephrosis one was aborted for hydrocephalus. 2 patients had cystic disease of the kidney on first post natal scan and 2 neonates' hydronephrosis had resolved. 15 neonates with persistent hydronephrosis were graded as follows. All SFU grades correlated with prenatal SFU grades except one.

\begin{tabular}{|c|c|c|c|}
\hline SFU Grade & $\begin{array}{c}\text { No. of } \\
\text { Cases }\end{array}$ & $\begin{array}{c}\text { No. of Cases } \\
\text { Resolved }\end{array}$ & Percentage \\
\hline Grade I & 1 & 1 & $100 \%$ \\
\hline Grade II & 2 & 2 & $100 \%$ \\
\hline Grade III & $5^{* *}$ & 0 & 0 \\
\hline Grade IV & $3^{*}$ & 0 & 0 \\
\hline \multicolumn{4}{|c|}{ Table 3. Severity of Hydronephrosis and Resolution } \\
\hline 3 cases lost follow up **1 case lost follow up.
\end{tabular}

\begin{tabular}{|c|c|c|c|}
\hline $\begin{array}{c}\text { SFU } \\
\text { Grade }\end{array}$ & $\begin{array}{c}\text { No. of } \\
\text { Cases }\end{array}$ & $\begin{array}{c}\text { No. of Cases with Post } \\
\text { Natal Pathology }\end{array}$ & Percentage \\
\hline Grade I & 1 & 0 & 0 \\
\hline Grade II & 2 & 0 & 0 \\
\hline Grade III & $5^{* *}$ & 5 & $100 \%$ \\
\hline Grade IV & $3^{*}$ & 3 & $100 \%$ \\
\hline \multicolumn{4}{|c|}{ Table 4. Severity of HN and Post Natal Pathology } \\
\hline *3 cases lost follow up. **1 case lost follow up. \\
\hline
\end{tabular}

All patients with SFU grade I/II or renal pelvis APD $<10$ mm showed resolution. Out of 6 cases, one baby was aborted and AHN resolved by birth in 2 cases, by 1 month in 2 cases and by 6 months in one case. Whereas all patients with SFU grade III/IV or APD $>10 \mathrm{~mm}$ had post natal pathology

A Micturating Cystourethrogram and Diuretic renogram was performed in all the cases with SFU 3/4.Four cases refused further evaluation. All the other cases had an obstructing cause (PUV in 2 cases, PUJO in 4 cases) except two which had Grade III vesico ureteric reflux. One case diagnosed as PUJ obstruction on Diuretic Renogram was found to have megaureter intraoperatively. 


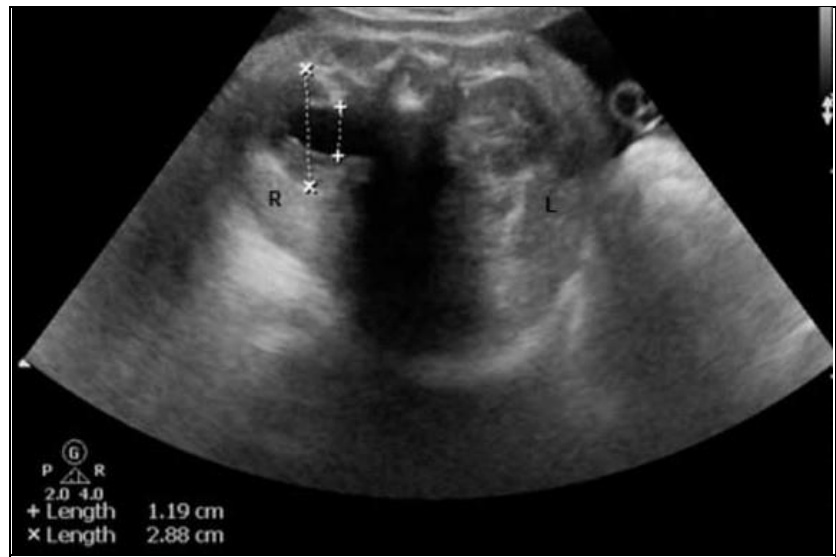

Figure 1. Antenatal Scan Showing Foetal Hydronephrosis

\section{DISCUSSION}

\section{Incidence of ANH}

Abnormalities of the urinary tract are reported to occur in $0.1-0.92 \%$ of pregnancies. ${ }^{5}$ This discrepancy in incidence relates partly to the timing of the antenatal ultrasound scan. Accurate visualisation of the pelvicalyceal system and renal parenchyma may not be possible before 18-20 weeks of gestation. In a prospective screening programme for foetal abnormalities in Sweden only 9\% of renal abnormalities were detected before 17 weeks of gestation, while 91\% were detected by 33 weeks. ${ }^{1}$ If a second ultrasound scan were to be performed in all pregnancies at 30 to 36 weeks, it is likely that reported incidence rates of hydronephrosis and vesicoureteric reflux would be higher. ${ }^{5}$ Incidence in our study was $0.134 \%$. Low incidence in our study may be related to low rates of antenatal ultrasound being done in the region or low incidence of the disease in the region or maybe a combination of both. In our study $80 \%$ of the cases were detected by 32 wks and $100 \%$ were detected by 36 wks.

\section{Severity of ANH}

In a systematic analysis on 25 studies, Sidhu et al., showed that isolated ANH resolved or stabilized in 98\% patients with APD $<12 \mathrm{~mm}$ as compared with 51\% with larger APD. ${ }^{6}$ In another meta-analysis on 1308 neonates from 17 studies, Liveraet al., found that the risk of postnatal pathology increased with the degree of antenatal pelvic dilatation, from $11.9 \%$ for mild, $45.1 \%$ for moderate, and $88.3 \%$ for severe hydronephrosis. ${ }^{4}$ In our study $33.33 \%$ of patients with mild hydronephrosis (APD $<10 \mathrm{~mm}$ ) had post natal pathology. In $66.66 \%$ of the cases hydronephrosis resolved. $83.33 \%$ with moderate $\mathrm{HN}$ and $100 \%$ in patients with severe $\mathrm{HN}$ had post - natal pathology. APD > $15 \mathrm{~mm}$ at any gestation represents severe hydronephrosis and requires close follow-up.

\section{Third Trimester Ultrasound}

The gestation at which hydronephrosis is detected and its course on sequential ultrasound scans has prognostic value. Almost $80 \%$ of foetuses diagnosed in the second trimester show resolution or improvement of findings ${ }^{7}$ with low likelihood of postnatal sequelae. Patients with persistence or worsening hydronephrosis in the third trimester show higher rates of postnatal pathology and require close follow-up ${ }^{7}$ Sairamet al., found that $88 \%$ cases with mild ANH resolved in utero or neonatal period, while one in three neonates with moderate to severe hydronephrosis persisting in the third trimester required postnatal surgery. ${ }^{5}$ Hence, an ultrasound in the third trimester is valuable for identifying foetuses that require postnatal evaluation and follow-up.

In our study, none had resolution of hydronephrosis, but 2 patients showed improvement of hydronephrosis in $3^{\text {rd }}$ trimester. Both of them had post-natal pathology. Improvement of hydronephrosis was not found to be of prognostic significance in our study.

\section{Post Natal Ultrasound}

All newborns with a history of ANH, including those in whom it had resolved prenatally, should undergo postnatal evaluation. Reports suggest that hydronephrosis that has resolved postnatally does not merit prolonged follow-up and has satisfactory outcome. ${ }^{1}$ A systematic review concluded that $98 \%$ patients with SFU grade $1-2$ or APD $<12 \mathrm{~mm}$ resolved, compared with $51 \%$ with APD $>12 \mathrm{~mm}$ or SFU 3-4.6

In our study, hydronephrosis resolved in all patients with SFU grade I/II or renal pelvis APD $<10 \mathrm{~mm}$. Hydronephrosis did not resolve in any of the [patients with SFU grade III/IV or renal pelvis APD $>10 \mathrm{~mm}$.

\section{Correlation between Post Natal Pathology and Severity on Postnatal USG}

Results of a meta-analysis showed that isolated ANH was five times more likely to stabilize if associated with SFU grade 1-2 or APD $<12 \mathrm{~mm}$ than with SFU grade $3-4$ or APD $>12 \mathrm{~mm}{ }^{6}$

In our study, none of the patients with SFU grade I/I or renal pelvic $\mathrm{ADP}<10 \mathrm{~mm}$ had any post natal pathology. Whereas, all the patients with SFU grade III/IV or renal pelvic APD $>10 \mathrm{~mm}$ had post natal pathology. Hence unilateral or bilateral hydronephrosis with APD up to $10 \mathrm{~mm}{ }^{8}$ have been followed successfully, relying on clinical features, ultrasonography and counselling parents for surveillance for UTI. Hydronephrosis resolves in most such patients during the first 2-years of life, and radiologic investigations or antibiotic prophylaxis is usually not necessary. The policy to follow these neonates with sequential ultrasonography to monitor for resolution of hydronephrosis therefore seems satisfactory.

\section{Vesico Ureteric Reflux}

VUR is present in 8-38\% patients with unilateral or bilateral $\mathrm{ANH}$, as compared with $<1 \%$ in the general population. ${ }^{9}$ While, there is increased risk of UTI; there is lack of evidence that antibiotic prophylaxis in patients with mild VUR confers clinical benefit. Multiple studies and a systematic review suggest that the severity of ANH does not correlate with the grade of reflux, 10 and that patients with VUR may have normal postnatal ultrasound.11 However, renal pelvic APD exceeding $10-11 \mathrm{~mm}$ is useful in identifying patients with severe VUR. ${ }^{12}$

In our study VUR was found in $13.3 \%$ of the cases. Degree of hydronephrosis did not correlate with the grade of reflux. However, all the cases were SFU grade III/IV.

\section{Posterior Urethral Valves}

Infants with posterior urethral valves require early urethral catheterization, correction of electrolyte abnormalities, treatment for possible complications and referral for surgical intervention. Cystoscopic ablation of the urethral valves is recommended. 13 
None of the patients in our study showed any signs of lower urinary tract obstruction in antenatal/post natal ultrasound. Consequently, PUV were not suspected and were discovered at MCU at 6wks. All the cases underwent Cystoscopic valve ablation. Renal functions remained stable on post operative DR.

\section{PUJ Obstruction}

While most experts suggest that pyeloplasty be considered in patients showing obstructed drainage and differential function below $40 \%$, others propose surgery at differential function below $35 \%$, or an obstructed renogram with prolonged $\mathrm{t}_{1 / 2}>20 \mathrm{~min} .{ }^{14}$

Conservative management is appropriate for infants with an obstructive pattern on diuretic renography and differential function exceeding $40 \%$. Serial ultrasonography is recommended 15 and repeat renography done if there is persistent or progressive hydronephrosis or parenchymal thinning. ${ }^{16} \mathrm{~A}$ reduction of differential renal function by more than $5-10 \%$ correlates with declining renal function, and the need for pyeloplasty. ${ }^{1}$

In our study 2 patients had unilateral PUJ obstruction and Differential function $<40 \%$. Both underwent pyeloplasty and differential function remained stable. One patient with PUJ obstruction with differential function $>40 \%$ was managed conservatively. Followed up with USG and DR. Renal function remained stable.

\section{Limitation}

Due to the short duration of the study the sample size taken was small.

\section{CONCLUSION}

The incidence of Antenatal Hydronephrosis was $0.134 \%$. Only patients with renal pelvic APD $>7 \mathrm{~mm}$ in third trimester have postnatal pathology, which should be taken as cut off. ANH is caused by transient causes, PUJ obstruction, UVJ obstruction, posterior urethral valves, VUR and cystic disease of kidney. Patients with SFU grade I/II HN will resolve and only need regular follow up with ultrasonogram. Patients with SFU grade III/IV will have a pathology that needs intervention. Pathology needs to be identified by MCU and diuretic renogram. Early relief of obstruction will prevent progressive renal damage.

\section{REFERENCES}

[1] Sinha A, Bagga A, Krishna A, et al. Revised guidelines on management of antenatal hydronephrosis. Indian J Nephrol 2013;23(2):83-97.

[2] Mallik M, Watson AR. Antenatally detected urinary tract abnormalities: more detection but less action. Pediatr Nephrol 2008;23(6):897-904.
[3] Dudley JA, Haworth JM, McGraw ME, et al. Clinical relevance and implications of antenatal hydronephrosis. Arch Dis Child Fetal Neonatal Ed 1997;76(1):F31-4.

[4] Livera LN, Brookfield DS, Egginton JA, et al. Antenatal ultrasonography to detect fetal renal abnormalities: A prospective screening programme. BMJ 1989;298(6685):1421-3.

[5] Sairam S, Al-Habib A, Sasson S, et al. Natural history of fetal hydronephrosis diagnosed on mid-trimester ultrasound. Ultrasound Obstet Gynecol 2001;17(3):191-6.

[6] Sidhu G, Beyene J, Rosenblum ND. Outcome of isolated antenatal hydronephrosis: a systematic review and meta-analysis. Pediatr Nephrol 2006;21(2):218-24.

[7] Feldman DM, DeCambre M, Kong E, et al. Evaluation and follow-up of fetal hydronephrosis. J Ultrasound Med 2001;20(10):1065-9.

[8] Coelho GM, Bouzada MC, Pereira AK, et al. Outcome of isolated antenatal hydronephrosis: a prospective cohort study. Pediatr Nephrol 2007;22(10):1727-34.

[9] Hodson EM, Wheeler DM, Vimalchandra D, et al Interventions for primary vesicoureteric reflux. Cochrane Database Syst Rev 2007;(3):CD001532.

[10] Phan V, Traubici J, Hershenfield B, et al. Vesicoureteral reflux in infants with isolated antenatal hydronephrosis. Pediatr Nephrol 2003;18(12):1224-8.

[11] Blane CE, DiPietro MA, Zerin JM, et al. Renal sonography is not a reliable screening examination for vesicoureteral reflux. J Urol 1993;150(2 Pt 2):752-5.

[12] Grazioli S, Parvex P, Merlini L, et al. Antenatal and postnatal ultrasound in the evaluation of the risk of vesicoureteral reflux. Pediatr Nephrol 2010;25(9):1687-92.

[13] Sarhan 0, Zaccaria I, Macher MA, et al. Long-term outcome of prenatally detected posterior urethral valves: single centre study of 65 cases managed by primary valve ablation. J Urol 2008;179(1):307-12.

[14] Salem YH, Majd M, Rushton HG, et al. Outcome analysis of pediatric pyeloplasty as a function of patient age, presentation and differential renal function. J Urol 1995;154(5):1889-93.

[15] Ransley PG, Dhillon HK, Gordon I, et al. The postnatal management of hydronephrosis diagnosed by prenatal ultrasound. J Urol 1990;144(2 Pt 2):584-7.

[16] Heinlen JE, Kropp BP, Frimberger DC. Progression of hydronephrosis correlates with worsening renal function in children. Conference: 2009 American Urological Association (AUA) Annual Meeting Chicago, IL, United States, Conference Publication. J Urol 2009;181:443. 